\title{
Scientific integrity, trust in science, and independence of research
}

\author{
Heikki Hokkanen ${ }^{1,2}$
}

Published online: 5 April 2019

(c) The Author(s) 2019

\section{Science in crisis?}

Celebrating the 10-year anniversary of APIS impact factor with this Special Jubilee Issue is shadowed by the apparent marginalization of and lack of trust in science in public life, and in political decision-making. In leading countries that foster scientific excellence, such as the United States, United Kingdom, and my home country Finland, public policy is increasingly based on other than solid scientific evidence, and key decision-makers publically belittle scientists. For example, a leading British politician dismissed consulting economists by stating 'People in this country have had enough of experts' (Clarke and Newman 2017). The Prime Minister of Finland was belittling the expertise of university professors and other academic staff in a TV interview (2 December 2015), while making a call for "those who could advise us on what to do in this [economic] situation". In the USA, uncomfortable scientific facts are replaced by "alternative truths" as a basis for policymaking (Tsipursky 2017). Why is it that while the general public largely has a high confidence and trust in science (Funk 2017), politicians seem to lack respect for scientific expertise?

Rush Holt, the CEO of the American Association for the Advancement of Science (AAAS), explained at the World Science Forum in Budapest in 2015 that "Policy makers do not think of science frequently, or crave scientific advice. They do not even know what to ask" (King 2016).

For us scientists, these developments should be alarming. Maybe we have to look into the way how science is operating: how science policy is formed, and how scientific institutions are run. After all, trust has to be earned.

Heikki Hokkanen

heikki.hokkanen@uef.fi; heikki.hokkanen@helsinki.fi

1 Department of Environmental and Biological Sciences, University of Eastern Finland, Kuopio, Finland

2 Department of Agricultural Sciences, University of Helsinki, Helsinki, Finland
Research results arising from within the stakeholder communities (e.g., industry-based research, or institutes serving a particular sector, and being funded by that sector) have always been viewed with suspicion by the critical public, while independent research institutes and universities traditionally have enjoyed high levels of public trust. It seems that this tradition is eroding, as research institutes and universities are changing their funding and operation principles. Increasingly, researchers are deprived of their academic freedom and are requested to conform to the "research strategy of the institution". Large proportion of funding is currently targeted, specifying exactly what the researcher is expected to study and how, leaving very little scope for independent innovations and creative problem solving.

Another aspect of evaluating whether scientists are trustworthy or not, is to look at the quality of their work. Under the intense pressure to produce a high number of publications, it is discomforting to learn that despite our efforts to peer review and to assure quality, the majority of published research findings are wrong. Professor John Ioannidis at Stanford University specializes in the conduct of scientific studies. He has found that in modern research, false findings may be the majority, or even the vast majority, of published research claims (Ioannidis 2005). Is this an outcome of the way our science policy is steered, and how the academic institutions are operating?

\section{The case of an EU-funded Horizon 2020 project}

An illustrative, personal case study concerning the described problematics, has been detailed earlier in the articles by Hokkanen (2017), Hokkanen and Menzler-Hokkanen (2018a, b, c), and Menzler-Hokkanen (2018).

I summarise here how a promising, pan-European research project addressing the call SFS-28-2017, with focus on ecostacking (Hokkanen 2017), was transformed from its original aspiration by a series of administrative and research policy decisions. As a result, a project intitially 
based on integrated biocontrol, was lost in translation (for details see Menzler-Hokkanen 2018). The fate and handling of the project EcoStack illustrates a lack of transparency concerning Intellectual Property (IP) rights and copyright protection at the EU-level. The process reveals how university administrators currently can steer and influence the kind of research they wish to have conducted at their institution. It also demonstrates the predatory behavior of the scientific community, and the inability of the funding organization (in this case the European Commission's DG Agriculture and Rural Development, and the Research Executive Agency) to follow and enforce basic ethical standards, and to foster integrity in research, which it funds (further details in Hokkanen and Menzler-Hokkanen 2018c).

The project proposal EcoStack was created, written (for most parts), and submitted by the University of Helsinki (UH) research team. The $10 \mathrm{M} €$ research project was approved for funding. In the end, however, the UH team was completely excluded from the project. The project was funded, however, based on the original submission, where the names of the UH team members have been replaced by other names, without mentioning the original project coordinator (PC), or other UH authors of the proposal. The funds originally allocated to $\mathrm{UH}$, have been distributed among consortium partners (Table 1), showing that they have been very well aware of the process. The respective research administrators at these institutions clearly have approved this procedure.

The loss of our original research ideas is amplified by the economic loss for the more than 2 years of work-without any compensation, which the project required from us. The

Table 1 Distribution of the UH share of the EcoStack budget as additional resource to EcoStack partners

\begin{tabular}{lc}
\hline Beneficiary & $\begin{array}{c}\text { Additional } \\
\text { funds in } €\end{array}$ \\
\hline University of Naples, Italy & 590,000 \\
Swedish University of Agricultural Sciences, Sweden & 185,000 \\
Institut supérieur d'agriculture Rhône-Alpes (ISARA), & 83,000 \\
$\quad$ France & \\
Rothamsted Research, United Kingdom & 80,000 \\
Jagiellonian University, Kraków, Poland & 60,000 \\
University of Turku, Finland & 60,000 \\
University of Aarhus, Denmark & 42,000 \\
University of Newcastle, United Kingdom & 30,000 \\
Julius Kühn Institute, Germany & 22,000 \\
University of Kassel, Germany & 15,000 \\
University of Coimbra, Portugal & 15,000 \\
University of Belgrade, Serbia & 15,000 \\
\hline
\end{tabular}

The Table shows the budget increases to the 11 partners over their original budgets (adapted from Hokkanen and Menzler-Hokkanen 2018c) original Project Coordinator and the UH research team lost in this process their contributed IP, the copyright of the concept and name of "EcoStack", the term "ecostacking", and significant parts of the text in the proposal. Large sections of our text are included in the funded version exactly as was originally proposed, with the exception that the original author's names are replaced by other names mainly from the University of Naples (Italy). In our view, this is plagiarism, violates the IP and copyright rights of UH team, alters the direction of the funded research (see discussion in MenzlerHokkanen 2018), and is ethically wrong. Norway's National Guidelines for Research Ethics in the Social Sciences, Law, Humanities and Technology (NESH 2006, p. 25) takes a clear position on this (Section 28): 'Plagiarism of others' text, material, ideas and research results is unacceptable and constitutes a serious breach of ethical standards.'

The official reply from the European Commission to our request to rectify the situation concerning the IP was that the case is difficult and should be settled in a civil court; the Ethics Helpdesk of the EU has declined to take a position. The advice that researchers need to seek justice in civil courts leaves individual researchers unprotected against predatory behavior, and against being robbed of their research ideas and funds, as in the case of EcoStack. Are European research administrators not willing to enforce fundamental principles of research ethics, integrity, and intellectual property rights, when it seems to pay off (Table 1)?

Besides having lost our IP and copyright rights in this process, we would like to point out that our work has been exploited also in sheer economic terms. It has become common to engage professional consulting companies to help scientists in writing research proposals for EU-funded competitive projects, such as the $\mathrm{H} 2020$ projects. These companies do part of the work in compiling, formulating, and submitting of the proposals on behalf of the consortium. This service, however, comes with a price. We know from experience that competent companies charge flat rate fee of $3000 €$ per partner for preparing stage one $\mathrm{H} 2020$ projects, and an equal sum per partner for stage two. If the proposal is successful, an additional success-rate fee of $1 \%$ of the budget is charged. If we assume that we at UH were writing the EcoStack proposal for the consortium as a consulting company, the payments to us would have been from the 24 EcoStack partners in total 244,000€. The UH team's input (e.g. writing of the whole text for a full Work Package on dissemination) certainly matches the work that a consulting company would have provided. In addition, the UH team contributed its own IP to the proposal, and other services, which a consulting company would not provide (see Fig. 1). 
Fig. 1 "EcoStack writing camp", organized and hosted by the UH team privately in Bavaria in July 2017. A consulting company does not provide such services, and certainly not for free to the consortium partners. Photo by Ingeborg Menzler-Hokkanen

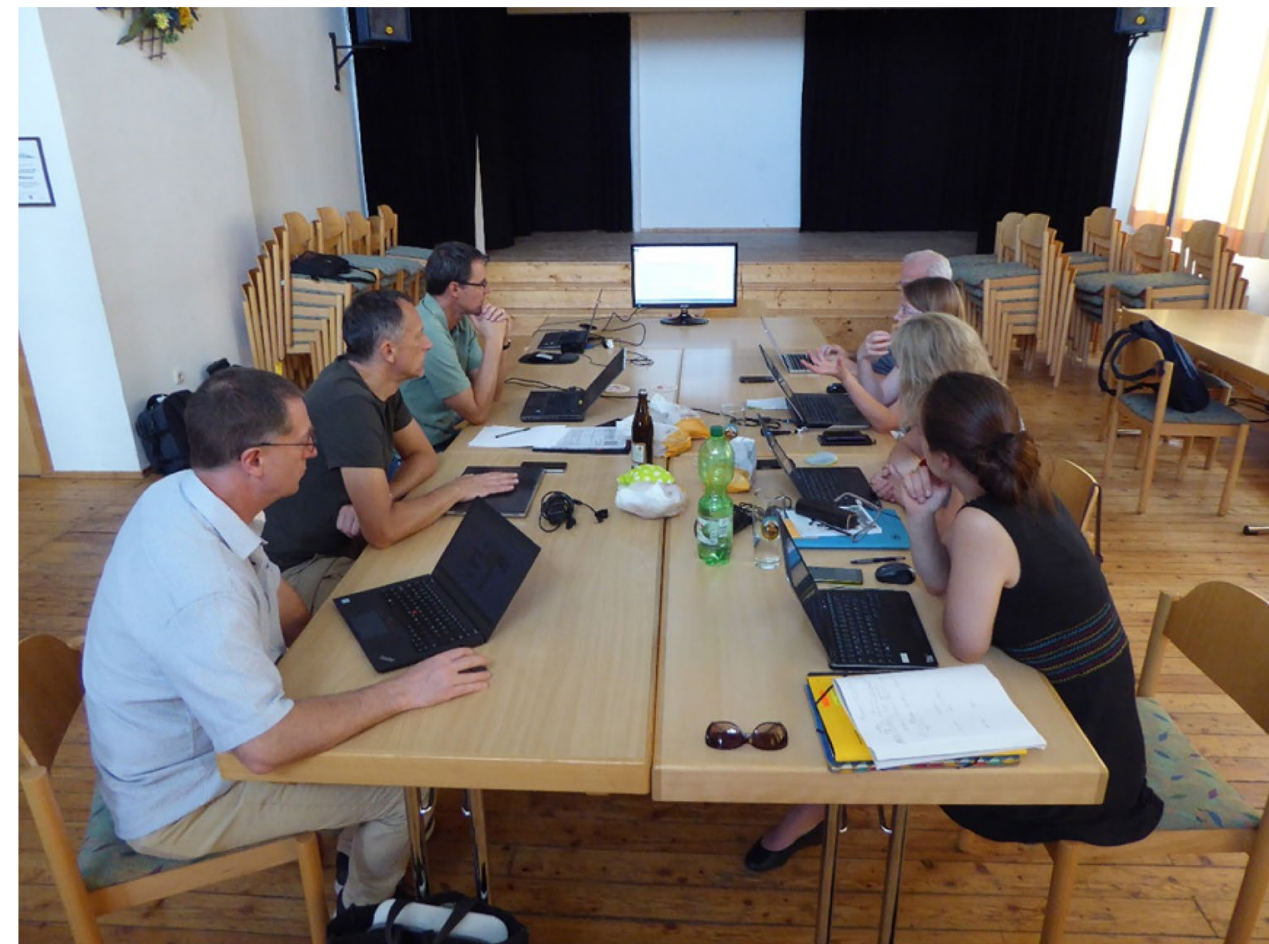

\section{Mafiaisation of science?}

In her book "Justice under siege" (Joly 2006) Eva Joly describes how mafia-like structures penetrate and control large parts of our society - a sort of mafiaisation takes place in the society. Mafiaisation of science includes the fear of research groups to lose access to project funding, if not playing by the unwritten rules. It includes also collusion and power ambitions by groups based on long-term joint interaction in organisations, which provide contacts and insights. It seems that the case of EcoStack is a perfect expression of this phenomenon in the sphere of science. It also seems that the mafiaisation of research is accepted by the funding organization, the European Commission.

Within the European research funding instruments, for many disciplines the financial allocations and research policies are controlled by discipline-specific small groups, or 'mafias' (in Eva Joly's words). If your research group is not included in these circles, the expectations to obtain funding are not high. This creates scientific inbreeding, which hampers progress within that particular field, as new and fresh ideas are not given a chance to prove themselves.

The same can be seen at many other levels, from private and public research institutions to commercial businesses, which eventually fail in their aspirations because they develop a culture that "cannot see outside the box." In these situations persons who try to point out flaws in the system and propose changes to rectify the situation, are usually sacked or kicked out-a typical fate of 'whistleblowers' (Scaturro 2018).

Joly (2006) pointed out that the mafiaisation of the society is related to the concept of 'white-collar crime' as developed by Sutherland (1949). Edwin Sutherland was the first person to study and to develop the theory of white-collar crime. He wanted people to understand that even well educated, respected individuals commit crime of deceit, motivated by financial gain. It does not involve physical violence. However, the aftermath of its greed is devastating and can ruin lives. It is not difficult to see a link between the writings of Sutherland (1949), Joly (2000, 2006), and EcoStack.

The events around the takeover of the EcoStack project directly clash with the principles of integrity in research, as formulated and described by the US National Academy of Sciences (NAS 2002). According to the NAS,

integrity in research is essential for maintaining scientific excellence and keeping the public's trust. The concept of integrity in research cannot, however, be reduced to a one-line definition. For a scientist, integrity embodies above all the individual's commitment to intellectual honesty and personal responsibility. It is an aspect of moral character and experience. For an institution, it is a commitment to creating an environment that promotes responsible conduct by embracing standards of excellence, trustworthiness, and lawfulness and then assessing whether researchers and administrators perceive that an environment with high 
levels of integrity has been created. .... Individuals and institutions should use these practices with the goal of fostering a culture in which high ethical standards are the norm, ongoing professional development is encouraged, and public confidence in the scientific enterprise is preserved.

It is clear that to increase the credibility, impact and respect of scientists, and the scientific, evidence-based approach to policy making, our scientific institutions and science funding must work better than in the case of EcoStack. The rise of pseudoscience and alternative facts as guiding principles for running our societies cannot be the future of humanity.

Acknowledgements Open access funding provided by University of Helsinki including Helsinki University Central Hospital.

Open Access This article is distributed under the terms of the Creative Commons Attribution 4.0 International License (http://creativeco mmons.org/licenses/by/4.0/), which permits unrestricted use, distribution, and reproduction in any medium, provided you give appropriate credit to the original author(s) and the source, provide a link to the Creative Commons license, and indicate if changes were made.

\section{References}

Clarke J, Newman J (2017) 'People in this country have had enough of experts': brexit and the paradoxes of populism. Critical Policy Studies 11:101-116. https://doi.org/10.1080/19460 171.2017.1282376

Funk C (2017) Mixed messages about public trust in science. Issues Sci Technol 34(1):86-88

Hokkanen HMT (2017) Ecostacking: maximising the benefits of ecosystem services. Arthropod Plant Interact 11:741. https://doi. org/10.1007/s11829-017-9575-8

Hokkanen HMT, Menzler-Hokkanen I (2018a) Insect pest suppressive soils: buffering pulse cropping systems against outbreaks of
Sitona weevils. Ann Entomol Soc Am. https://doi.org/10.1093/ aesa/say019

Hokkanen HMT, Menzler-Hokkanen I (2018b) Urgent need to develop ecostacking techniques to enhance ecosystem services in cropping systems. Arthropod Plant Interact. https://doi.org/10.1007/s1182 9-018-9620-2

Hokkanen HMT, Menzler-Hokkanen I (2018c) Developing ecostacking techniques for pollen beetle management in oilseed rape. Arthropod Plant Interact. https://doi.org/10.1007/s11829-018-9650-9

Ioannidis JP (2005) Why most published research findings are false. PLoS medicine 2(8):e124. https://doi.org/10.1371/journ al.pmed.0020124

Joly E (2000) Notre affaire à tous. Edition Les Arenes, Paris, 253 pp

Joly E (2006) Justice under siege. Arcadia Books Ltd, London, 178 pp

King A (2016) Science, politics and policymaking. EMBO Rep 17:1510-1512. https://doi.org/10.15252/embr.201643381

Menzler-Hokkanen I (2018) Ecosystem services for pollen beetle control in oilseed rape: ethical aspects of ecostacking-lost in translation? Arthropod-Plant Interact. https://doi.org/10.1007/ s11829-018-9638-5

NAS (2002) Integrity in scientific research: creating an environment that promotes responsible conduct. National Academy of Sciences. The National Academies Press, Washington, D.C, 216. https://doi.org/10.17226/10430

NESH (2006) National Guidelines for Research Ethics in the Social Sciences, Law, Humanities and Technology. National Committees for Research Ethics in Norway. https://www.etikkom.no/globa lassets/documents/english-publications/guidelines-for-researchethics-in-the-social-sciences-law-and-the-humanities-2006.pdf

Scaturro R (2018) Defining whistleblowing. International Anti-Corruption Academy, Research Paper Series No. 05. Laxenburg, Austria. pp 1-21. https://www.iaca.int/images/Research/Research_paper _05_Ruggero_Scaturro_final.pdf

Sutherland EH (1949) White collar crime. Dryden Press, New York, 272

Tsipursky G (2017) How to fight "Alternative Facts" in politics. Sci Am 77:12

Publisher's Note Springer Nature remains neutral with regard to jurisdictional claims in published maps and institutional affiliations. 